\title{
Action Adventure Game Based for Virtual Faculty Environment
}

\author{
H.A. Sulaiman, S. H. Muhamadi, A. N. Che Pee, M. H. L. Abdullah, M. H. Zakaria, S. S. Rahim
}

\begin{abstract}
Aim of this game is to promote Faculty of Information and Communication Technology (FTMK) and teach a basic C++ programming using game. FTMK is a faculty at University Teknikal Malaysia Melaka (UTeM) that offer computer science and information technology course. The Savior is an action adventure game that consist of several mission and story that need player to follow. The mission is involving of answer the question and fight the enemy. This game is action adventure where the game is not totally full educational game. It also has some entertainment and action in this game. The objective of this project is to study on action adventure game for educational based game. Next, to design and develop educational based action game that concentrating on promoting FTMK. Finally, to evaluate, debug and then conduct a survey for the corresponding action adventure game. This project has four phases, which is Concepting phase, Per-Production phase and Post Production phase. The expected result is to let people know more about FTMK and more understand $\mathrm{C}++$ programming language.
\end{abstract}

Keywords: Virtual Environment, Action, Adventure, Game

\section{INTRODUCTION}

UTeM is one of the technical IPTA university in Malaysia [1-4]. In UTeM there is many sophisticated facilities such as lecture room, high technology laboratory, robotic laboratory and high voltage laboratory. FTMK is one of the faculty located under UTeM, Durian Tunggal, Melaka. In FTMK there are six department which is Media Interactive (MI), Software Engineering (SE), Intelligent Computing and Analytic (ICA), Computer System and Communication (CSC), Administration and Technical and Support Department.

Revised Manuscript Received on July 30, 2020.

* Correspondence Author

H.A. Sulaiman*, Center for Advanced Computing Technology (C-ACT), Fakulti Teknologi Maklumat Dan Komunikasi, Universiti Teknikal Malaysia (UTeM), 76100 Durian Tunggal, Melaka, Malaysia.

Syazwan Harith Bin Muhamad, Former Student of Universiti Teknika Malaysia Melaka, Durian Tunggal, Melaka, Malaysia.

A. N. Che Pee, Center for Advanced Computing Technology (C-ACT), Fakulti Teknologi Maklumat Dan Komunikasi, Universiti Teknikal Malaysia (UTeM), 76100 Durian Tunggal, Melaka, Malaysia.

M. H. L. Abdullah, Center for Advanced Computing Technology (C-ACT), Fakulti Teknologi Maklumat Dan Komunikasi, Universiti Teknikal Malaysia (UTeM), 76100 Durian Tunggal, Melaka, Malaysia.

M. H. Zakaria, Center for Advanced Computing Technology (C-ACT), Fakulti Teknologi Maklumat Dan Komunikasi, Universiti Teknikal Malaysia (UTeM), 76100 Durian Tunggal, Melaka, Malaysia.

S. S. Rahim, Center for Advanced Computing Technology (C-ACT) Fakulti Teknologi Maklumat Dan Komunikasi, Universiti Teknikal Malaysia (UTeM), 76100 Durian Tunggal, Melaka, Malaysia.

(C) The Authors. Published by Blue Eyes Intelligence Engineering and Sciences Publication (BEIESP). This is an open access article under the CC BY-NC-ND license (http://creativecommons.org/licenses/by-nc-nd/4.0/)
The purpose of this project is to promote FTMK to people in UTeM and all around Malaysia by developing a game that called The Savior. The Savior is develop using Unity 3D game Engine. This game is focusing on people from 18 to 25 year old.

\section{LITERATURE REVIEWS}

\section{A. Action and Adventure Game}

Action game are considered as one of the important elements that operated in many genre nowadays where it involves fast pace animation scene between player and non-player character (NPC).

It requires quite an attention from the player where most of the action games concentrates on making each game scene explicitly show the real conditions of the respective game. For example, Call of Duty games shows fast pace action between player and the enemies. [5-13].

Originally on of the earliest game genre was adventure game based.

It was implemented using text based gaming system where the player need to pay attention to each line of text that appeared in the screen.

Thus, player needs to plan the attacks or to moving or not by simply using text based command that has been instructed to the player to use when playing the game.

As the technology grows all over the years from 1980s to high tech graphics system using Graphical Processing Unit (GPU) chipset, the game turned into graphical gameplay where player be able to move the character or player using keyboard or mouse or any other input.

One of the adventure games was a Colossal Cave game where it takes the player into a role model that go through interactive storyline where player needs to explore and solve puzzle[14-21].

The player needs to find or collect any mission artifacts as instructed by the NPC or combine any artifacts in order to get the things for the mission.

NPC usually give significant hints to the player in order to complete the mission.

\section{B. Edutainment Game}

Edutainment is a combination between entertainment and education [22-46].

Instead of traditional approach of learning through television or video channel, edutainment has give birth to many education based games either in PC or consoles. Edutainment is widely used for teach the students specific knowledge. 


\section{Action Adventure Game Based for Virtual Faculty Environment}

\section{Game Based Learning}

Game based learning (GBL) is defined as a gameplay which will give the learning outcomes.

In general, GBL is actually is another technique of teaching student in order to give more understandings and immersion into subjects or topics that they have to learn. The game based learning method can draw the player into virtual environments that look and feel like a familiar event.

To develop a game that will include an education is a challenge. Edutainment are sometimes fails to give the player a dynamic learning curve which is an improvement to the player to keep on learning through the game.

This happens because most of the developer create a the gameplay that is requires repetitive action and somehow demotivate the player to keep on playing [6, 8, 14-17, 19-21, 29-31, 35, 39, 47].

If the developer success in developing a game that is both fun to learn and play, the user might have the desire to make something by playing the game. For an example, if the music game is both fun and entertaining, it could give an inspiration to the player to make music.

Therefore, game-based learning method is giving a positive effect to the player as it will make the player keep on playing to win the game by performing actions, experimentation until the player do it correctly and experiencing the consequences along the way.

\section{EXISTING GAME}

Ryse: Son of Rome is one of the favorite and anticipating action-adventure game that use hack and slash gameplay type and using third perspective character view Player control the hero as the leader soldier to fight and kill all his enemies in order to protect its empire.

Player just must follow its objective and storyline in order to win the game. The gameplay is linear. Figure 1 shows the screenshot of the gameplay for that game.

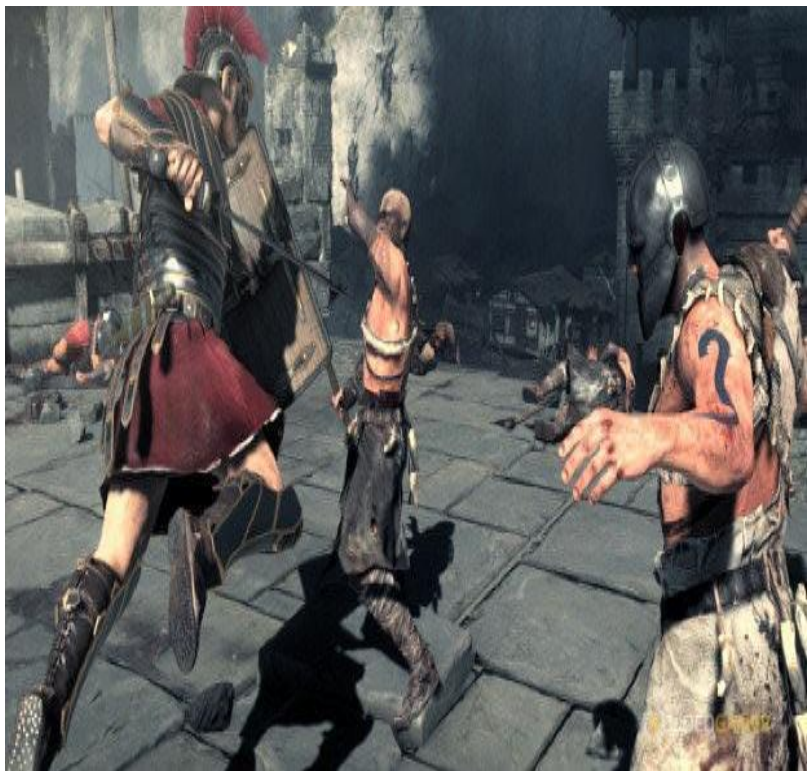

Figure 1: Screenshot of Ryse: Son of Rome gameplay

Meanwhile The Final Fantasy Crisis Core game is also considered one of the the genre type chosen for this project. This game category is action based role-playing game (RPG) in which player control the main character in interactively open world environment. Action RPG game usually allows the player to move the main character throughout vast open world environment, talks to various type of NPC, engage with various size of monsters and boss monsters. Once player complete the story and missions, the game is over.

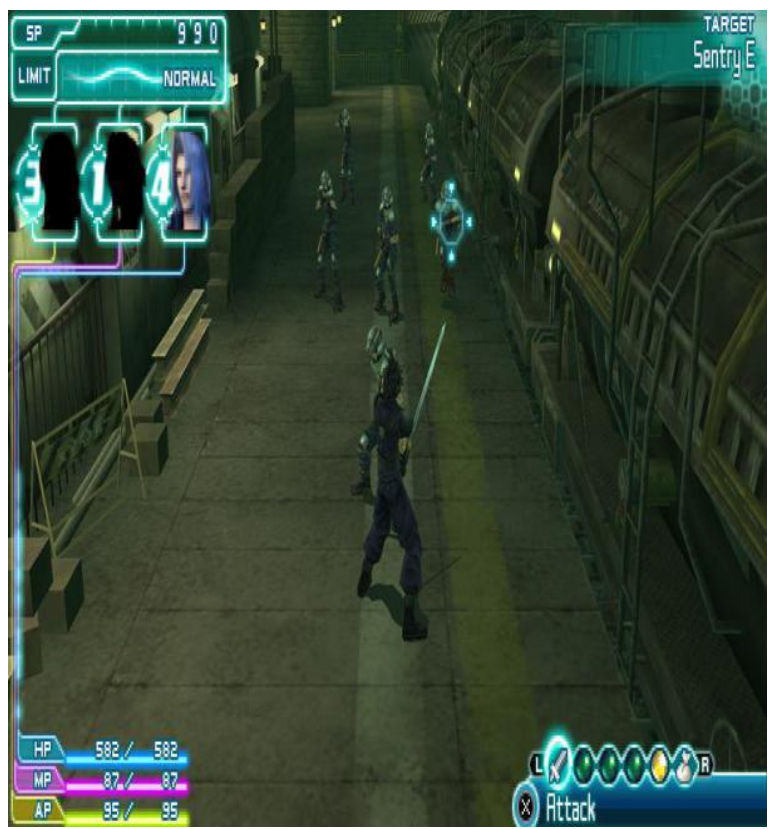

Figure 2: FF Crisis Core gameplay

\section{IMPLEMENTATION}

\section{A. Production of Text}

Text used in this game is quite simple because of the platform is mobile that has smaller screen size. To prevent confusing or misunderstanding to player, the font type and color used must be consistent and easy to read. Table 1 shows the production of text used in game.

\section{B. Production of Graphic}

Production of graphic consist of background image, character, asset, texture and everything that involve with graphic in game.

For the hero character and NPC character was created using Autodesk Maya.

The texture of the character is has been downloaded from internet and edited using Photoshop.

The enemy character was download from Mixamo website. Figure 3 and 4 shows the characters.

Production of Sound This game only produces music background. Music background keeps looping. Production of sound in game will make player more immerse and enjoy while playing. The sound was download from internet. Table 2 explains the sound data.

\section{Integration of Game Component}

Unity 5 consist of three programming languages, which is C sharp, Unity Script (JavaScript for unity) and Boo. C sharp was used for develop this game.

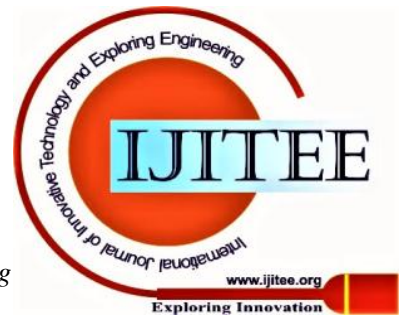


Table 1: Production of Text

\begin{tabular}{|c|c|c|c|c|}
\hline Interface & Text & Font Type & Font Color & Font Size \\
\hline \multirow{4}{*}{ Main Menu } & Play Button & Night Warrior & Black & 40 \\
\cline { 2 - 5 } & Control Button & Night Warrior & Black & 40 \\
\cline { 2 - 5 } & Quit Button & Night Warrior & Black & 40 \\
\hline \multirow{4}{*}{\begin{tabular}{c} 
Pause Menu \\
\cline { 2 - 5 }
\end{tabular}} & Restart Button & Night Warrior & Black & 40 \\
\cline { 2 - 5 } & Home Button & Night Warrior & Black & 40 \\
\cline { 2 - 6 } & Quit Button & Night Warrior & Black & 40 \\
\hline \multirow{2}{*}{$\begin{array}{c}\text { Game Over } \\
\text { Page }\end{array}$} & Restart Button & Night Warrior & Black & 40 \\
\cline { 2 - 6 } & Quit Button & Night Warrior & Black & 40 \\
\hline \multirow{2}{*}{\begin{tabular}{c} 
Win Page \\
\hline
\end{tabular}} & Quit Button & Night Warrior & Black & 40 \\
\hline
\end{tabular}
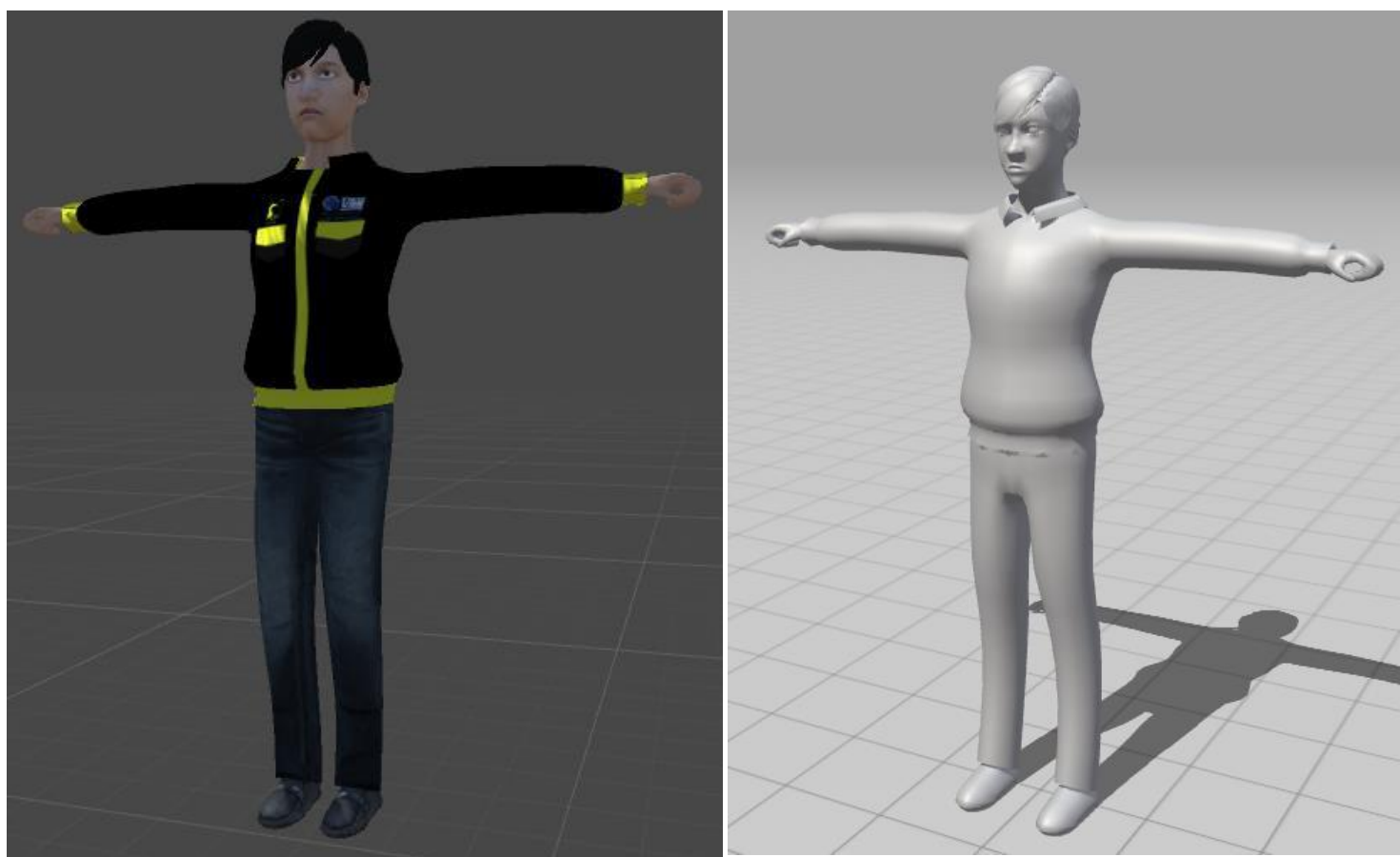

Figure 3: Character with Textures Applied Figure 4: Character Development in 3D

Table 2: Production of Sound

\begin{tabular}{|l|l|}
\hline Type of Sound & Production \\
\hline Background Music & Online Resources \\
\hline
\end{tabular}

\section{DISCUSSION}

Figures below shows all the scripting codes that has been implemented.

The implementation status is that each compartment in the game accomplish within the time given. This is because the project has a guide from Gant chart and draft design before implement in game. Therefore, the implementation phase as expected can be launch perfectly in PC.

\section{A. Scripting for the Game}

Several scripting or programming code has been implemented in the game in order to make the game work smoothly in this virtual environment game.

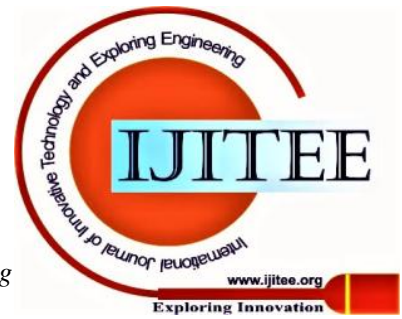




\section{Action Adventure Game Based for Virtual Faculty Environment}

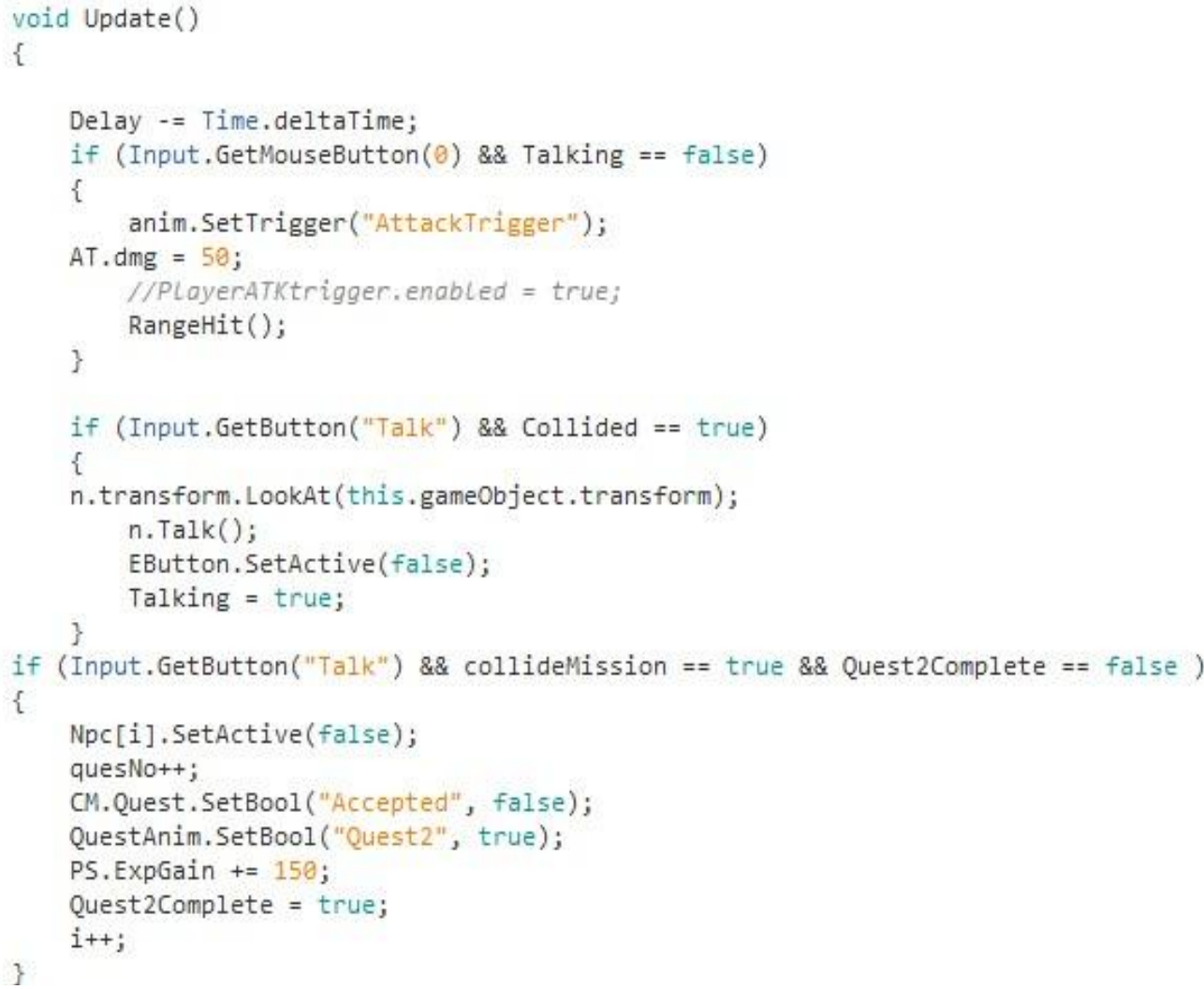

Figure 5: Player Attack set up

void Range()

EnemyChase $=$ PlayerMove.transform.position;

distance $=$ Vector 3 . Distance (transform, position, player, transform, position)

if (distance < RunRange \&\& distance > walkRange)

RB.AddForce(transform. forward * (Runspeed))

Ustep = speed * Time deltatime (

transform lookAt (Enemychase)

anim SetBool ("Running" true)

animisetsotbool (Moying" false)

anim.SetBool ("Walk", false);

if

(distance < walkRange \&\& distance > HitRange)

RB. AddForce (transform, forward * (speed)):

transform. LookAt (EnemyChase);

anim.SetBool ("Running", false);

\}.

anim.SetBool ("Walk", true)

if (distance <= HitRange)

anim.SetBool ("Running", false): anim.SetBool ("Moving", false): RangeHit ();

\}

void RangeHit()

\{

distance $=$ Vector3.Distance (transform.position, player.transform.position);

if (distance $<=$ HitRange \&\& Delay $<=\theta$ )

\{

transform. LookAt (EnemyChase);

enemattackTrigger. enabled = true;

anim.SetBool ("AttacklTrigger", true);

anim.SetBool ("Moving", false);

Delay $=5$

Invoke ("Hide", timeTrigger);

\}

void Dead ()

if (EnemcurHealth $<=\theta$ )

gameobject. GetComponent<EnemyAi> ( ).enabled = false;

gameobject. GetComponent<BoxCollider> ().enabled = false;

gameobject.Getcomponent<Rigidbody> (). Usedravity = false;

gameobject. GetComponent<BoxCollider> ().isTrigger = false;

Figure 6: Enemy Behaviors toward player

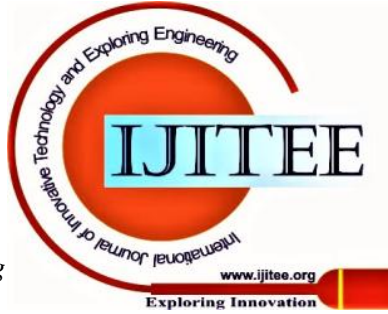




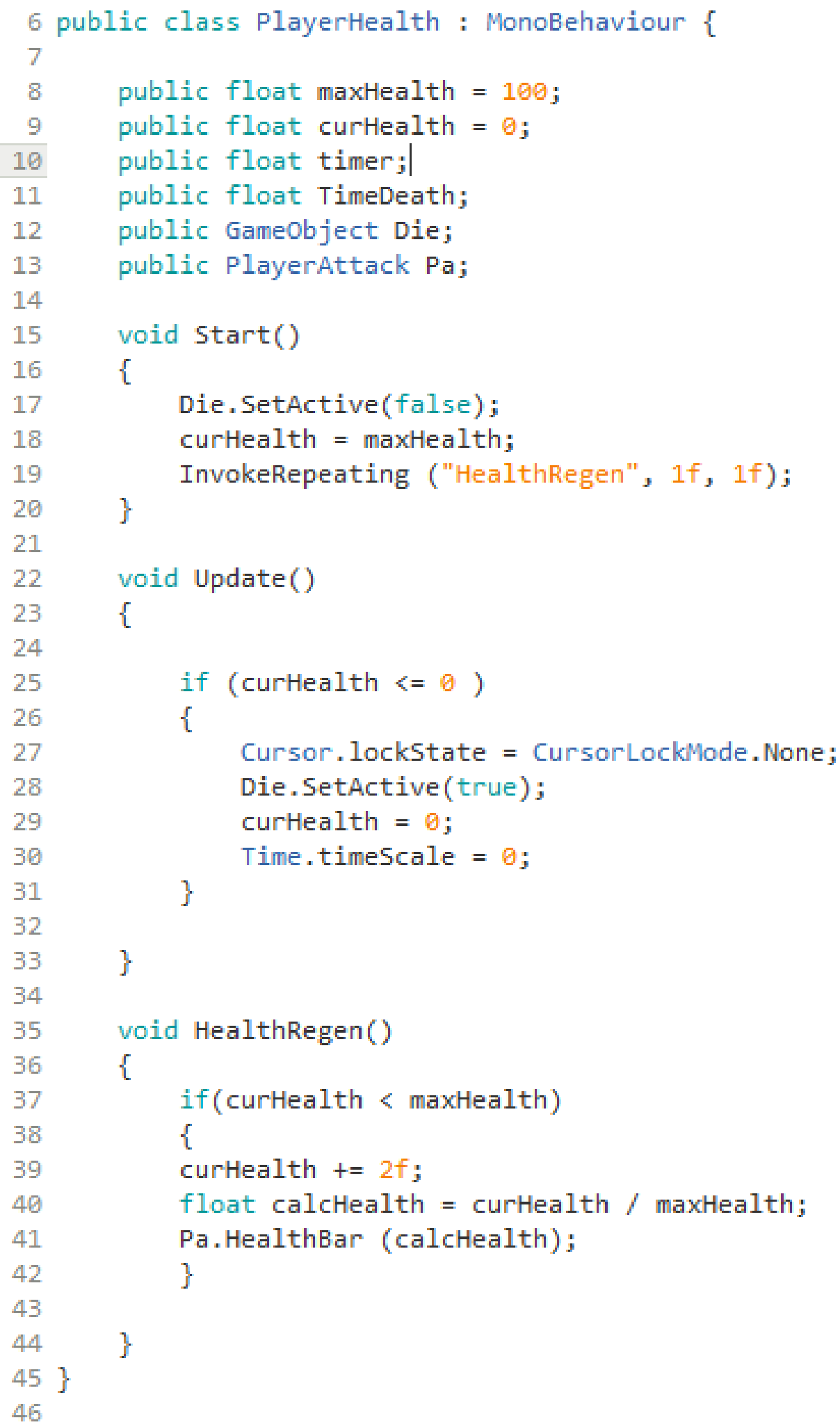

Figure 7: Player Health set up

\section{TESTING AND DISCUSSION}

Testing is to identify on how much the project work well. From overall cases, testing is the best way figure out whether the objective is achievable or not. This chapter will describe the activity involve in testing phase. The testing is conducted among gamer, casual gamer and non-gamer between the target users.

The ambition for this test plan is to present Action Adventure Game Mechanics that base on FTMK environment. 


\section{Action Adventure Game Based for Virtual Faculty Environment}

20 respondents commit for this test consist of target audience from 18 years old to 25 years old. Method for this test plan is by using questionnaire.

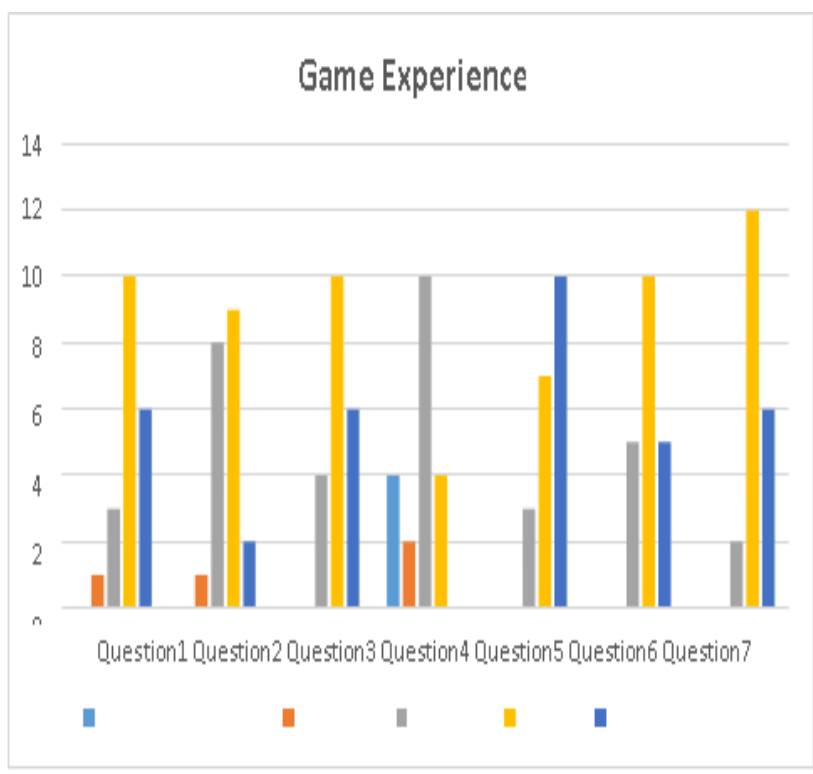

Figure 8: Data of User Game Experiences

Figure 8 explain about the data of game experience. Based on question 1 , most of the respondent agree that the story of the game is interesting and only one respondent disagree.

Most of the respondent also agree with question 2 statement that say the game is pressure and only one of the respondents disagree with that. Most respondent feel fun when playing this game base on question 3 .

Next is question 4, 4 of the respondents feel annoy when playing this game, 10 of them feel a little bit annoy and 6 of them do not feel annoy.

From question 5 most of the player immerse into the game that player feel like they were in the character place.

Question 6, state about the excited feeling when playing this game. Most of them agree that they feel excited.

Extremely agree and average have a same value. Last question is state about the challenge of the game 6 of them feel really challenges, 12 of the feel challenges and 2 of them feel that the challenges is not too hard.

\section{CONCLUSION}

This game project can be proving it meet the objective. From the test result, they are interest when test the game. The user give ideas on how to make the game more interesting. They also help to create a game that can be accept by everyone.

This show that game can get user interest to involved. From there, the game can meet the user need to play the game.

\section{ACKNOWLEDGMENT}

We would like to thank support to the Universiti Teknikal Malaysia Melaka for game facility and environment support for this project.

\section{REFERENCES}

1. Hashim, U.R.a.b., et al. Development of learning object for engineering courses in UTeM. in 2009 International Conference on Engineering Education (ICEED). 2009.

2. Mutalip, Z.B.A., N.B.A. Hamid, and N.I.B. Hassan. Emphasizing OBE in UTeM subjects to develop human capital. in 2009 International Conference on Engineering Education (ICEED). 2009.

3. Shahbodin, F., M. Yusoff, and C.K.N.C.K. Mohd. ICT + $P B L=$ holistic learning solution: UTeM's experience. in 2011 Sixth International Conference on Digital Information Management. 2011.

4. Tan, P.H., C.K. Gan, and K.A. Baharin. Techno-economic analysis of rooftop PV system in UTeM Malaysia. in 3rd IET International Conference on Clean Energy and Technology (CEAT) 2014. 2014.

5. Inoue, A., T. Fukunaga, and R. Ishikawa. Transformable Game Controller and Its Application to Action Game. in 2019 IEEE Conference on Virtual Reality and 3D User Interfaces (VR). 2019.

6. Joselli, M., et al. Mindninja: Concept, Development and Evaluation of a Mind Action Game Based on EEGs. in 2014 Brazilian Symposium on Computer Games and Digital Entertainment. 2014.

7. Lee, E., et al., Game Data Mining Competition on Churn Prediction and Survival Analysis Using Commercial Game Log Data. IEEE Transactions on Games, 2019. 11(3): p. 215-226.

8. Liu, X. and S. Zheng. Study of vehicle-cross action model for unsignalized intersection based on dynamic game. in 2010 International Conference on Mechanic Automation and Control Engineering. 2010.

9. Novak, E. and J. Tassell. Video Games that Improve 'Learning to Learn': Focus on Action Video Game Play Elements. in 2017 IEEE 17th International Conference on Advanced Learning Technologies (ICALT). 2017.

10. Oktriono, K. and H. Chong. Developing $3 D$ action puzzle game application "The Mechanic" using UNITY. in 2015 IEEE Conference on e-Learning, e-Management and e-Services (IC3e). 2015.

11. Pauwels, P., et al. The Role of Game Rules in Architectural Design Environments. in 2011 Third International Conference on Games and Virtual Worlds for Serious Applications. 2011.

12. Satria, T.G., W. Sardjono, and F.M. Panggabean. A System Dynamics Computer Model To Assess The Effects Of Action Games On The Development Of Children With Special Need. in 2019 International Conference on Information Management and Technology (ICIMTech). 2019.

13. Schmück, E., et al. Principles underlying the design of a cognitive training game as a research framework. in 2019 11th International Conference on Virtual Worlds and Games for Serious Applications (VS-Games). 2019.

14. Brassai, B., et al. GeoQuesting: Mobile adventure game and web-based game editor. in 2014 IEEE 12th International Symposium on Intelligent Systems and Informatics (SISY). 2014. 
15. Chou, Y., et al. Running Tommy@: Developing a Digital Adventure Game Based on Situated Learning to Promote Learners' Concepts of Earthquake Escape. in 2012 IEEE Fourth International Conference On Digital Game And Intelligent Toy Enhanced Learning. 2012.

16. Hsu, Y., C. Lin, and J. Shih. Developing Multi-player Digital Adventure Education Game with Motion Sensing Technologies. in 2013 IEEE 13th International Conference on Advanced Learning Technologies. 2013.

17. Kuehn, E. and J. Sieck. Design and implementation of location and situation based services for a pervasive mobile adventure game. in 2009 IEEE International Workshop on Intelligent Data Acquisition and Advanced Computing Systems: Technology and Applications. 2009.

18. Lope, R.P.D. and N. Medina-Medina. Using UML to Model Educational Games. in 2016 8th International Conference on Games and Virtual Worlds for Serious Applications (VS-GAMES). 2016.

19. Rajalingam, V.R. and S. Samothrakis. Neuroevolution Strategies for Word Embedding Adaptation in Text Adventure Games. in 2019 IEEE Conference on Games (CoG). 2019.

20. Sommeregger, P. and G. Kellner. Brief Guidelines for Educational Adventure Games Creation (EAGC). in 2012 IEEE Fourth International Conference On Digital Game And Intelligent Toy Enhanced Learning. 2012.

21. Torrente, J., et al. Introducing Accessibility Features in an Educational Game Authoring Tool: The \&\#60;e-Adventure > Experience. in 2011 IEEE 11th International Conference on Advanced Learning Technologies. 2011.

22. Buripanith, S., et al. Traffic Story: An android edutainment game for Thailand traffic law learning. in 2014 Third ICT International Student Project Conference (ICT-ISPC). 2014.

23. Chatzidimitris, T., et al. Mobile Augmented Reality edutainment applications for cultural institutions. in IISA 2013. 2013.

24. Colace, F., et al. Work in Progress: Bayesian Networks for Edutainment. in Proceedings. Frontiers in Education. 36th Annual Conference. 2006.

25. Dae-Hyeon, S., P. Jae-Wan, and L. Chil-Woo. Implementation of edutainment contents for Touch-Face system. in 2008 International Conference on Control, Automation and Systems. 2008.

26. Duangphasuk, P., C. Sakunvaraklang, and K. Thanintharatharn. Edutainment tools and VIDEO podcasting for E-learning courses in university. in 2017 10th International Conference on Ubi-media Computing and Workshops (Ubi-Media). 2017.

27. Fernandez, J., P. Lopez, and J. Oliva. A Distributed Multirobot System Based on Edutainment Robots. in Proceedings of the 2005 IEEE International Conference on Robotics and Automation. 2005.

28. Fikry, A., R. Yusob, and Z. Hussein. The effect of Malaysian customer characteristics on intention to adopt edutainment services in digital home. in 2013 World Congress on Computer and Information Technology (WCCIT). 2013.

29. Halloluwa, T., et al. Interaction design for tablet based edutainment systems for mathematical education of primary students. in 2015 Fifteenth International
Conference on Advances in ICT for Emerging Regions (ICTer). 2015

30. Jantke, K.P., et al. Computer-aided cutting-edge research on history for home edutainment and exploratory learning. in The 1st IEEE Global Conference on Consumer Electronics 2012. 2012.

31. Jiawei, H., et al. A special edutainment system based on somatosensory game. in 2015 6th IEEE International Conference on Software Engineering and Service Science (ICSESS). 2015.

32. Juan, C., R. Canu, and M. Giménez. Augmented Reality Interactive Storytelling Systems Using Tangible Cubes for Edutainment. in 2008 Eighth IEEE International Conference on Advanced Learning Technologies. 2008.

33. Kwak, S.S., et al. Field trials of the block-shaped edutainment robot HangulBot. in 2012 7th ACM/IEEE International Conference on Human-Robot Interaction (HRI). 2012.

34. Lien, Y. Mobile Edutainment System -- National Palace Museum as an Example. in 2015 3rd International Conference on Future Internet of Things and Cloud. 2015.

35. Ling, Y., H. Gu, and X. Wang. An Ontology-Based Development Framework for Edutainments. in 2008 International Seminar on Business and Information Management. 2008.

36. Meeanan, L., et al. The edutainment of virtual music instrument for Thai xylophone (Ranad-ek). in 2012 International Conference for Internet Technology and Secured Transactions. 2012.

37. Mon, C.S., K.M. Yap, and A. Ahmad. A Preliminary Study on Requirements of Olfactory, Haptic and Audio Enabled Application for Visually Impaired in Edutainment. in 2019 IEEE 9th Symposium on Computer Applications \& Industrial Electronics (ISCAIE). 2019.

38. Phunsa, S., N. Potisarn, and S. Tirakoat. Edutainment -Thai Art of Self-Defense and Boxing by Motion Capture Technique. in 2009 International Conference on Computer Modeling and Simulation. 2009.

39. Sarkar, S.P., B. Sarker, and S.K.A. Hossain. Cross platform interactive programming learning environment for kids with edutainment and gamification. in 2016 19th International Conference on Computer and Information Technology (ICCIT). 2016.

40. Shitiq, H.A.A.H. and R. Mahmud. Using an edutainment approach of a Snake and Ladder game for teaching Jawi script. in 2010 International Conference on Education and Management Technology. 2010.

41. Sundjaja, A.M. and E. Ekawati. Evaluation of edutainment e-marketing model implementation at Bank Mandiri Museum. in 2015 International Seminar on Intelligent Technology and Its Applications (ISITIA). 2015.

42. Takase, N., J. Botzheim, and N. Kubota. Robot Edutainment on Walking Motion of Multi-legged Robot. in 2013 Second International Conference on Robot, Vision and Signal Processing. 2013.

43. Wang, Q., W. Tan, and B. Song. Research and Design of Edutainment.

Published By:

Blue Eyes Intelligence Engineering and Sciences Publication 


\section{Action Adventure Game Based for Virtual Faculty Environment}

in 2007 First IEEE International Symposium on Information Technologies and Applications in Education. 2007.

44. Yamane, M., M. Yamamoto, and T. Watanabe. Development of a real-space sharing edutainment system based on communication support with make-believe play. in SICE Annual Conference 2011. 2011.

45. Yan, W., Z. MingZhang, and L. XiangYong. Edutainment technology - a new starting point for educational development of China. in 2007 37th Annual Frontiers In Education Conference - Global
Engineering: Knowledge Without Borders, Opportunities Without Passports. 2007.

46. Yun, C., J. Ahn, and Y. Kim. An implementation of computer vision technique for an edutainment robot with a visual programming language. in 2013 10th International Conference on Ubiquitous Robots and Ambient Intelligence (URAI). 2013.

47. Hsu, S., et al. From Traditional to Digital: Factors to Integrate Traditional Game-Based Learning into Digital Game-Based Learning Environment. in 2008 Second IEEE International Conference on Digital Game and Intelligent Toy Enhanced Learning. 2008. 